УДК 347.9

DOI https://doi.org/10.17308/vsu.proc.law.2021.2/3385

\title{
О ПРОБЛЕМАХ УЧАСТИЯ ПРОКУРОРА В РАССМОТРЕНИИ СУДАМИ ГРАЖДАНСКИХ ДЕЛ
}

\author{
Е. Р. Ергашев \\ Уральский государственный юридический университет \\ Поступила в редакцию 10 марта 2021 г.
}

\begin{abstract}
Аннотация: исследуются теоретические и практические аспекты участия прокурора в расслотрении судали гражданских дел. Проводится анализ проблем правового регулирования деятельности прокурора, участвуюшего в расслотрении судами гражданских дел. Исследуются правовой статус, бборль участия и роль прокурора в гражданскол процессе. Делается вывод об участии прокурора в гражданскол процессе как важной составляющей деятельности по обеспечению исполнения закона и дополнительной гарантии защиты прав и свобод человека и гражданина, о необходимости приведения в соответствие ФЗ «О прокуратуре РФ» и ГПК $P \Phi$, а также закрепления в действующел законодательстве о прокуратуре критериев определенных понятий.
\end{abstract}

Ключевые слова: прокуратура, прокурор, суд, гражданский процесс, прокурорский надзор, правовой статус прокурора, процессуальные права и облзанности прокурора.

\begin{abstract}
: the article examines the theoretical and practical aspects of the participation of the prosecutor in the consideration of civil cases by the courts. The analysis of the problems of legal regulation of the activities of the prosecutor involved in the consideration of civil cases by the courts. The article examines the legal status, forms of participation and the role of the prosecutor in the civil process. The conclusion is made about the participation of the prosecutor in the civil process as an important component of the activity to ensure the implementation of the law and an additional guarantee of the protection of human and civil rights and freedoms, it is necessary to bring the Federal Law@On the Prosecutor's Office of the Russian Federation@ and the Code of Civil Procedure of the Russian Federation into compliance, as well as to be enshrined in the current legislation on the prosecutor's office criteria for certain concepts.

32 Key words: prosecutor is Office, prosecutor, court, civil procedure, and prosecutor's supervision, the legal status of the prosecutor, procedure rules and the duties of a prosecutor.
\end{abstract}

В современной литературе одной из дискуссионных проблем участия прокурора в рассмотрении судами гражданских дел является его процессуальный правовой статус. К. С. Юдельсон объясняет наличие данной проблемы тем, что закон наделяет прокурора почти всеми полномочиями сторон в процессе, в частности, теми, которые касаются предоставления доказательств, в доказывании обстоятельств дела. В то же время

(C) Ергашев E. P., 2021 
Федеральный закон «О прокуратуре Российской Федерации» ${ }^{1}$ выводит на первый план надзор за соблюдением Конституции РФ и исполнением законов, действующих на территории Российской Федерации ${ }^{2}$. Здесь необходимо сделать уточнение. Безусловно, осуществление прокурорского надзора является важнейшей функцией прокуратуры, однако в теории прокурорского надзора выделяют также и другие фрункции ${ }^{3}$, одной из которых является содействие прокуратуры осуществлению правосудия. Обозначенная К. С. Юдельсоном проблема имеет как теоретический, так и практический характер, поскольку результат его решения определяет взаимоотношения между субъектами гражданского процесса и позволяет установить границы полномочий, т. е. прав и обязанностей, прокурора при рассмотрении судами гражданских дел.

В литературе изложены несколько позиций по данному вопросу. Сторонники первой - А. Ф. Козлов, А. А. Ференс-Сороцкий, М. С. Строгович считают, что прокурор по своему правовому процессуальному статусу занимает положение истца в гражданском процессе ${ }^{4}$. Основной аргумент сторонников данной концепции заключается в следующем. Действующее законодательство предусматривает состязательный судебный процесс с двумя сторонами разбирательства. После того как прокурор подает исковое заявление в суд для возбуждения гражданского дела, в деле появляется потенциальный ответчик. Наличие ответчика предполагает наличие противоположной стороны, а именно истца. Из чего сторонники данного подхода делают однозначный вывод, в соответствии с которым прокурор, инициируя гражданский процесс, занимает положение истца в деле и соответственно является стороной судебного разбирательства.

А. А. Ференс-Сороцкий, не отрицая дискуссионности исследуемого вопроса, также приравнивает прокурора в процессе к стороне, т. е. к истцу. Аргументами подобного суждения, по мнению этого автора, является невозможность осуществления органами прокуратуры надзорной фрункции по отношению к суду, поскольку в противном случае это приведет к нарушению принципа независимости судебной системы, являющегося фундаментом в теории разделения властей. Прокурор в гражданском процессе реализует те же права и выполняет те же обязанности, что и истец: при подаче искового заявления он должен соблюдать предусмотренные законодательством требования к форме искового заявления, представлять суду доказательства и др. В то же время, справедливо отмечает А. А. Ференс-Сороцкий, правовой процессуальный статус прокурора и истца не идентичен, поскольку на прокуроре, в отличие от стороны в процессе, не

${ }^{1}$ О прокуратуре Российской Федерации : федер. закон от 17 января 1992 г. № 2202-1. Доступ из справ.-правовой системы «КонсультантПлюс».

${ }^{2}$ См.: Юдельсон К. С. Советский гражданский процесс. М., 1956. С. 105.

${ }^{3}$ См.: Ергашев E. Р. Прокурорский надзор в Российской Федерации. Курс лекций. Екатеринбург, 2016. С. 18.

${ }^{4}$ См.: Козлов А. Ф. Вопросы гражданского процесса в свете решений XXVII съезда КПСС. Свердловск, 1987. С. 33-43 ; Ференс-Сороикий А. А. Прокурор в гражданском судопроизводстве // Правоведение. 1992. № 4. С. 91-95. 


\section{Вестник ВГУ. Серия: Право}

лежит обязанность уплачивать государственную пошлину, оплачивать судебные расходы. Прокурор обращается в суд в защиту публичных интересов, а также в защиту частных интересов лишь тогда, когда субъекты сами по причинам, предусмотренным в законе, не в силах этого сделать. В данном случае публичный и частный интересы совпадают. Прокурор и субъект спорного материального правоотношения являются соистцами, при этом не связанные позицией друг друга. Это суждение подтверждается действующим законодательством, закрепляющим положения, в соответствии с которым в случае отказа от иска прокурора лицо, в защиту которого было подано исковое заявление, может настаивать на продолжении дела по существу. Процессуальное положение прокурора, отмечает А. А. Ференс-Сороцкий, должно быть аналогично процессуальному положению других лиц, участвующих в деле. Если прокурор возбуждает гражданское дело, предъявляя иск, он является стороной в процессе истцом. Взаимоотношения суда с прокурором определяются так же, как и взаимоотношения со стороной ${ }^{5}$.

Противоположную точку зрения занимает М. А. Викут, полагая, что сторона - обязательно субъект спора о праве, субъект спорного правоотношения, в основе которого лежит материально-правовой, субъективный интерес к процессу ${ }^{6}$.

Т. Н. Маслова отмечает, что прокурор в гражданском процессе занимает самостоятельную роль, обеспечивая законность при рассмотрении гражданских дел, а также оказывает правовую помощь судуㄱ․

Как представляется, первая позиция (изложенная М. А. Викутом) не выдерживает критики. Аргументы, опровергающие ее содержание, приведены в положениях, закрепленных в ст. 34 и 38 ГПК РФ. В ст. 34 ГПК РФ указаны лица, участвующие в деле, к которым относятся стороны,

третьи лица, прокурор, лица, которые обращаются в судебные органы

으 за защитой прав, свобод и законных интересов других лиц, и некоторые другие лица. В ст. 38 ГПК РФ содержатся положения, регулирующие стороны гражданского процесса, обозначающие, что ими являются истец и ответчик. При этом в законе не содержится нормативное определение сторон, т. е. истца и ответчика. Стороны обладают определенными, традиционно утвердившимися в теории гражданского процесса признаками, что отличает их от других субъектов гражданского процессуального права.

В ч. 2 ст. 38 ГПК РФ содержатся положения о том, что лицо, в защиту прав которого исковое заявление подано другими субъектами, извещается судом о возникшем процессе и участвует в судебном разбирательстве в качестве истца.

${ }^{5}$ См.: Ференс-Сороцкий А. А. Указ. соч.

${ }^{6}$ См.: Викут M. A. Правовое положение прокурора, предъявившего иск в интересах другого лица // Вопросы теории и практики прокурорского надзора. 1994. № 10. C. 135 .

${ }^{7}$ См.: Маслова Т. Н. Проблемы участия прокурора в гражданском судопроизводстве : дис. ... канд. юрид. наук. Саратов, 2002. С. 13. 
Отсюда следует вывод, в соответствии с которым в случае обращения прокурора в суд с иском стороной (истцом) по делу будет именно то лицо, в интересах которого подано исковое заявление. Это наглядно свидетельствует о несостоятельности рассматриваемой позиции.

Сторонники второй точки зрения (М. С. Шакарян, А. Ф. Клейнман, С. В. Курылев, К. С. Банченко-Любимова, М. А. Викут, Ю. И. Лутченко, Д. М. Чечот, В. М. Перфильев) придерживаются мнения о том, что прокурор в гражданском месте занимает положение процессуального истца или истца в процессуальном смысле ${ }^{8}$. В основном аргументация этих ученых строится на отграничении материальной заинтересованности в исходе разрешения судом гражданского дела и процессуальной заинтересованности. Материальная заинтересованность субъекта (материальный интерес) в исходе дела означает, что принятое судебное решение будет прямо влиять на права, обязанности и интересы данного субъекта, так как после принятия судом определенного акта лицо приобретет право либо должно будет исполнить обязанность. Процессуальная заинтересованность в деле (процессуальный интерес) означает, что субъект заинтересован в том, чтобы дело было рассмотрено, разрешено в соответствии с положениями законов и чтобы по делу было принято какое-то решение. Материальный и процессуальный интерес одновременно имеют только стороны судебного разбирательства, поскольку они являются субъектами спорного материального правоотношения. Прокурор в таком качестве не выступает, соответственно он имеет лишь процессуальную заинтересованность, что объясняется, прежде всего, его задачами, обозначенными в Федеральном законе «О прокуратуре Российской Федерации». Исходя из этого, сторонники второй точки зрения полагают, что прокурор - это процессуальный истец, поскольку имеет лишь процессуальную заинтересованность в деле.

M. С. Шакарян рассматривает данную проблему с позиции главной задачи прокуратуры - укрепления законности во всех отраслях права, в том числе в сфрере гражданского процессуального права. Автор не отрицает очевидного факта, что действующее гражданско-процессуальное законодательство РФ относит прокурора к лицам, участвующим в деле. Однако по своему процессуальному положению прокурор отличается от остальных лиц, участвующих в рассмотрении судом гражданского дела. Отличие это непосредственно связано с задачей прокурора по обеспечению прав, свобод, интересов граждан, интересов общества и государства, что обусловливает наличие специальных полномочий прокурора, которых не может быть у других субъектов в гражданском судопроизводстве. Рассуждая о проблеме процессуального положения прокурора в граждан-

${ }^{8}$ См.: Чечот Д. М. Участники гражданского процесса. М., 1960. С. 177-178 ; Банченко-Любимова $K$. С. Участие прокурора в суде первой и второй инстанций по гражданским делам. М., 1963 ; Викуm M. A. Стороны - основные лица искового производства. Саратов, 1968. С. 44-46 ; Клейнлан А. Ф Советский гражданский процесс. М., 1954. С. 129 ; Курылев С. В. Объяснения сторон как доказательство в советском гражданском процессе. М., 1956. 


\section{Вестник ВГУ. Серия: Право}

ском процессе, М. С. Шакарян делает акцент на том, что статус прокурора зависит от фрормы его участия в процессе. Проблематичной представляется ситуация, при которой прокурор подает исковое заявление в защиту прав и интересов граждан, неопределенного круга лиц и интересов государства. По мнению автора, участие прокурора в процессе в качестве истца является исключительно способом реализации предоставленных ему фрункций по обеспечению прав и интересов граждан. Деятельность прокуратуры по защите лиц в судах и надзорная деятельность никак не противоречат одна другой. Более того, с позиции автора, при инициировании гражданского дела в суде, сочетание этих ффункций повышает возможность реальной защиты нарушенных или оспариваемых прав и законных интересов граждан, организаций, общества в целом и Российской Федерации. Исходя из этого прокурор при обращении с исковыми требованиями в суд является стороной, а именно истцом исключительно с процессуальной точки зрения, т. е. процессуальным истцом ${ }^{9}$.

Таким образом, критикуя аргументы, касающиеся соотношения процессуальных прав и обязанностей прокурора и истца по объему, противники отнесения прокурора к стороне в процессуальном смысле и вообще к стороне спора аргументируют свою точку зрения тем, что сам законодатель не наделяет прокурора всей полнотой процессуальных возможностей в процессе, в связи с чем прокурора нельзя приравнять к истцу. Поскольку прокурор никоим образом не связан с материальным правоотношением, то такое право, как заключение мирового соглашения, ему не требуется, так как лицо (прокурор), не являясь участником материального правоотношения, не может распоряжаться субъективными материальными правами и обязанностями. Именно поэтому и необходим, по мнению Г. Л. Осокиной, термин «процессуальный истец», который

в отличие от других предложенных в теории терминов наиболее уда의 чен ${ }^{10}$. Например, термин «заявитель иска», предлагаемый М. А. Викут, не отражает всей полноты процессуальных возможностей прокурора, поскольку ограничивается лишь правом обращения в суд за защитой прав ${ }^{11}$.

При этом, когда в деле участвует прокурор как «процессуальный» и истец материальный, процессуальное соучастие недопустимо. Данное суждение обусловлено отсутствием у прокурора материального интереса в исходе дела, поскольку он никоим образом не связан со спорным материальным правоотношением, не являясь его субъектом. Однако ст. 40 ГПК РФ требует наличия определенных условий для соучастия в процессе. Все перечисленные условия связаны с участием лиц в спорных материальных правоотношениях.

${ }^{9}$ См.: Шакарян M. С. Субъекты советского гражданского процессуального права. М., 1970. С. 295.

${ }^{10}$ См.: Осокина Г. Л. Гражданский процесс. Общая часть : учебник. 3-е изд., перераб. М., 2013. С. 232-242.

${ }^{11}$ См.: Викут M. A. Стороны - основные лица искового производства. С. 46. 
Следующий аргумент сторонников второй позиции строится на анализе норм гражданско-процессуального законодательства. Законодатель в ст. 34 ГПК РФ отделяет прокурора и сторон по делу, однако сторонники данной позиции положения ст. 131 ГПК РФ, посвященной требованиям к исковому заявлению, трактуют так, что они касаются исключительно истца. На этом основании в литературе истца приравнивают к прокурору - процессуальному истцу, который обращается в суд с заявлением и обязан соблюдать требования ст. 131 ГПК РФ $\Phi^{12}$. Однако данное суждение проблематично, поскольку в обозначенной статье нигде не говорится о том, что указанные требования адресованы только истцу. Исковое заявление должно содержать наименование истца, место его жительства, обстоятельства, на которых основаны требования истца, однако всё это может быть соблюдено другим субъектом, не являющимся стороной по делу: представителем, государственным органом и некоторыми другими, в том числе и прокурором. Более того, ч. 3 ст. 131 содержит дополнительные требования, соблюдение которых возложено исключительно на прокурора, подающего заявление в суд. Обозначенный фракт в очередной раз свидетельствует о наличии разницы между процессуальным положением прокурора и истца.

В литературе, сторонники третьей точки зрения (Н. А. Чечина, А. Л. Иванов, А. А. Власов) ${ }^{13}$ рассматривают прокурора в гражданском процессе исключительно как представителя государства, т. е. прокурор в судебном разбирательстве, как бы странно это ни звучало, не относится ни к сторонам, ни к иным процессуальным фигурам. Аргументация приверженцев указанной позиции строится в основном на базе тех целей и задач, которые возложены на органы прокуратуры Российской Федерации. То есть прокурор в гражданском процессуальном праве рассматривается через призму роли прокурора в жизни общества в целом. А. Л. Иванов связывает ч. 1 ст. 1 Федерального закона «О прокуратуре Российской Федерации» и ст. 2 ГПК РФ, отмечая что рассмотрение и разрешение гражданских дел обеспечивает защиту прав, свобод и интересов граждан, организаций, прав и интересов РФ, ее субъектов, муниципальных образований ${ }^{14}$. Согласно позиции А. Л. Иванова, прокурор, осуществляя надзор, способствует достижению перечисленных задач. Однако необходимо внести небольшое уточнение. С одной стороны, безусловно, после осуществления надзорной деятельности и выявления нарушений законов прокурор вправе и обязан отреагировать на выявленные нарушения, в том числе путем подачи искового заявления в суд. Тем самым прокурор продолжает свою деятельность по обеспечению законности и

${ }^{12}$ См.: Осокина Г. Л. Указ. соч. С. 237.

${ }^{13}$ См.: Чечина Н. А. Гражданский процесс : учебник. Изд. третье, перераб. и доп. М., 2001 ; Власов А. А. Участие прокурора в гражданском и арбитражном судопроизводстве // Вестник Моск. ун-та МВД России. 2009. № 4 ; Иванов А. Л. Прокурор как лицо, участвующее в деле в российском гражданском судопроизводстве : проблемы определения правового статуса // Там же.

${ }^{14}$ См.: Иванов А. Л. Указ. соч. С. 85. 


\section{Вестник ВГУ. Серия: Право}

защите прав и интересов субъектов. Но с другой стороны, в зале судебного заседания прокурор не осуществляет надзорную функцию, поскольку суд является полностью независимым органом. На этом основании предлагается связывать ст. 2 ГПК РФ с ч. 3 ст. 1 Федерального закона «О прокуратуре Российской Федерации», где указана не менее важная функция прокуратуры - участие прокурора в рассмотрении судами дел, в которых прокурор содействует осуществлению правосудия, о которой почему-то забывают многие теоретики и практики, связывая прокуратуру исключительно с надзором. Как справедливо отмечает А. А. Власов, независимо от фрормы участия прокурора в гражданском процессе, перед ним стоит одна единственная задача - содействие осуществлению правосудия ${ }^{15}$.

По мнению Н. А. Чечиной, прокурор в гражданском процессе олицетворяет публичный интерес, а также заинтересованность государства в обеспечении законности, которая выражается в защите прав, свобод, интересов граждан, прав и свобод государства, его составных частей, местных образований. По этой причине относить прокурора к стороне или к третьим лицам в процессе не допускается, к тому же прокурора не охватывают материальные правовые последствия судебных актов ${ }^{16}$.

Фигура прокурора в гражданском судопроизводстве, справедливо отмечает В. Ю. Шобухин, олицетворяет собой именно прокурора, все участники судебного процесса относятся и воспринимают его исключительно как прокурора, ст. 45 ГПК РФ предусматривает участие в судебном процессе прокурора, а не процессуального истца. Согласно ч. 2 ст. 38 ГПК РФ истцом признается лицо, в интересах которого начато дело. Иного содержания в понятие истца ГПК РФ не вкладывает. У прокурора отсутствует какой-либо собственный интерес в деле, и это является одной из особенностей его статуса. Стремление прокурора обеспечить защиту

прав и законных интересов граждан, общественных организащий, обще-

이 ства и государства, торжество закона в равной мере свойственно и суду. Если рассмотреть сущность и назначение органов российской прокуратуры, выявить причины введения в гражданский процесс такой фигуры, как прокурор, определить цели и задачи, преследуемые им, а также проанализировать ряд иных фракторов, не акцентируя при этом внимания на законодательной стороне данного вопроса, то придем, на наш взгляд, к тем же выводам, которые выражены в концепции К. С. Юдельсона ${ }^{17}$.

В литературе приводятся суждения противников данной позиции, основанные на том, что наличие двух фрорм участия прокурора в процессе свидетельствует о том, что процессуальный статус прокурора в разных случаях разнится, и что аргумент тех, кто считает, что статус прокурора стабилен независимо от формы участия, несостоятелен, поскольку на

${ }^{15}$ См.: Власов А. А. Участие прокурора в гражданском и арбитражном судопроизводстве (по ГПК РФ и АПК РФ 2002 г.) : метод. пособие. М., 2004. С. 4.

${ }^{16}$ См.: Чечина Н. А. Указ. соч. С. 55.

${ }^{17}$ См.: Шобухин B. О некоторых вопросах участия прокурора в гражданском процессе // Арбитражный и гражданский процесс. 2007. № 3. С. 8-9. 
практике это не так. Однако факты, случаи из судебной практики, как правило, не приводятся.

Е. В. Васьковский еще в начале прошлого века пытался обосновать термин «правозаступник», который в отличие от представителя иных субъектов, выступающих для защиты прав третьих лиц, защищает индивидуальные права и свободы ради общественного, государственного интереса ${ }^{18}$. Как представляется, нет нужды «подводить» прокурора под какой-то процессуальный статус, поскольку закон четко выделяет прокурора как самостоятельную фигуру, обусловленную его особой ролью в гражданском процессе. Данная позиция охватывает обе формы участия прокурора при рассмотрении судами гражданских дел, что не вызывает дополнительных проблем при рассмотрении данного аспекта. Совокупность прав и обязанностей не изменяется в зависимости от формы участия прокурора, что делает его постоянным представителем государства.

Однако данная позиция имеет определенные недостатки, основной из которых связан с вопросом, что делает представитель государства (публичной власти) в процессе, где имеет место спор по частному делу. Представляется, что подобное решение временное и обусловлено, с одной стороны, сложной экономической обстановкой в государстве, а с другой - наличием значительного числа социально незащищенных лиц, не имеющих возможности самостоятельно защищать свои законные права и интересы, которые призваны защищать органы прокуратуры Российской Федерации. Отсюда проблемы, связанные с инициированием прокурором гражданского дела в суде (ч. 1 ст. 45 ГПК РФ).

Часть 1 ст. 45 ГПК РФ предоставляет прокурору возможность подачи искового заявления в защиту прав, свобод и интересов граждан, прав и интересов государства, его субъектов и муниципальных образований. Однако установлены определенные ограничения при подаче прокурором заявления в защиту граждан, которые самостоятельно не могут сделать это по причине состояния здоровья, возраста, недееспособности и других уважительных причин.

В литературе положения ст. 45 ГПК РФ вызывают многочисленные дискуссии. Так, А. С. Толстых отмечает, что вроде бы эти положения расширяют круг лиц, в защиту которых может выступить прокурор, но в то же время не нарушает ли это состязательности? Граждане в данном случае сами в состоянии воспользоваться правом на судебную защиту ${ }^{19}$. А. Ю. Рожков полагает, что расширительное толкование перечня дел, по которым прокурор подает заявления без ограничений, приведет к нарушению принципа диспозитивности и равенства всех перед судом и законом $^{20}$.

${ }^{18}$ См.: Васьковский Е. В. Курс гражданского процесса. М., 1913. С. 296.

${ }^{19}$ См.: Tолстых A. C. Прокурор в гражданском процессе : современные проблемы. URL: http://docplayer.ru/29445615

${ }^{20}$ См.: Рожков А. Ю. Необходимость и целесообразность участия прокурора в гражданском и арбитражном процессе // Вестник Воронеж. ин-та МВД России. 2014. № 2. C. 59. 
Поддерживая его в этом, А. В. Китаева предлагает внести положение в ГПК РФ, которое указывало бы на недопущение расширительного толкования обозначенного перечня ${ }^{21}$.

Высказанная позиция не выдерживает критики, поскольку, во-первых, из положений ст. 45 четко следует, что обсуждаемый перечень носит закрытый характер, что само по себе означает невозможность расширительного толкования. Во-вторых, возражения по поводу нарушения равенства перед судом и состязательности детально рассмотрены выше и не являются критичными. В-третьих, не совсем понятно, как расширительное толкование категории дел, по которым прокурор может обращаться в защиту граждан, нарушит принцип диспозитивности. Обозначенный принцип не следует путать с принципом диспозитивности в материальном праве. Дело в том, что в процессуальных отраслях он означает возможность сторон своими действиями в рамках процессуального законодательства повлиять на судьбу материальных прав и обязанностей. Часть 2 ст. 45 ГПК РФ лишает прокурора возможности заключать мировое соглашение, к тому же прокурор не является стороной материального правоотношения. Следовательно, он не в состоянии повлиять и, тем более, нарушить принцип диспозитивности в гражданском процессе.

Следующая категория проблем обусловлена пробелами правового регулирования. Согласно положениям, предусмотренным ст. 45 ГПК РФ, прокурор обращается к защите прав и интересов граждан лишь в случаях, если они в силу здоровья, возраста, недееспособности и других уважительных причин не в состоянии сделать это самостоятельно. В связи с этим возникает множество вопросов, связанных с определением причины здоровья и возраста. Каковы возрастные рамки? Наличие каких болезней препятствует гражданину самостоятельно обратиться в суд? Сложности возникают и при толковании того, что понимать под «другими уважительными причинами». Данное положение является абстрактным

을 и требует изменений закона, разъясняющих данные понятия. В связи с этим А. В. Китаева предлагает либо конкретизировать ст. 45 ГПК РФ, либо исключить положение о «других уважительных причинах ${ }^{22}$. Представляется более верным внести уточнения в данную норму, поскольку исключение указанной формулировки вообще приведет к ограничению

40 полномочий прокуратуры в данной сфере и, как следствие, увеличению оставленных без внимания нарушений прав граждан. В законе необходимо определить критерии «уважительных причин», определенные ориентиры. При этом следует отметить, что разъяснение уважительных причин в ведомственных актах Генерального прокурора нецелесообразно, поскольку для суда указанные документы не имеют значения.

Еще одна проблема правового регулирования участия прокурора в рассмотрении судом гражданских дел связана с несоответствием нор-

${ }^{21}$ См.: Kuтаева A. B. Актуальные проблемы участия прокурора в гражданском процессе // Междунар. науч. журнал «Инновационная наука». 2016 . № 3. C. 58 .

${ }^{22}$ Там же. С. 59. 
мативных положений, содержащихся в Федеральном законе «О прокуратуре Российской Федерации» и ГПК РФ. Так, исходя из содержания положений ст. 27 Федерального закона «О прокуратуре Российской Федерации», в случае нарушения прав и свобод человека и гражданина, защищаемых в порядке гражданского судопроизводства, когда пострадавший по состоянию здоровья, возрасту или иным причинам не может лично отстаивать в суде или арбитражном суде свои права и свободы или когда нарушены права и свободы значительного числа граждан либо в силу иных обстоятельств нарушение приобрело особое общественное значение, прокурор предъявляет и поддерживает в суде или арбитражном суде иск в интересах пострадавших. Из чего следует, что подача заявления является как правом, так и обязанностью прокурора, а в ст. 45 ГПК РФ - это только право. В вопросе правового статуса прокурора, его полномочий, приоритет должен отдаваться спещиальному закону, а именно Федеральному закону «О прокуратуре Российской Федерации». К тому же, выявив нарушение прав граждан, прокурор вправе и обязан отреагировать на выявленное нарушение закона, что вытекает из целей и задач, для достижения которых была создана прокуратура РФ. В положениях, данных ст. 27, существует еще одно противоречие. В ст. 27 говорится о значительном числе граждан, а в ст. 45 - о неопределенном круге лиц. Данная коллизия приводит на практике к дополнительным трудностям, обусловленным неурегулированностью указанного аспекта, в связи с чем представляется необходимым привести действующее законодательство в соответствие.

Изложенные аргументы дают возможность сделать вывод, в соответствии с которым: во первых, участие прокурора в рассмотрении судами гражданских дел является важной составляющей деятельности по обеспечению исполнения закона и дополнительной гарантией защиты прав и свобод человека и гражданина; во-вторых, необходимо привести правовые нормы Федерального закона «О прокуратуре Российской Федерации» и ГПК в соответствие, а также закрепить в действующем законодательстве о прокуратуре критерии определенных понятий, разъяснение которых в ведомственных актах Генерального прокурора РФ нецелесообразно, поскольку для суда они не имеют значения.

\section{Библиографический список}

Банченко-Любилова $К$. С. Участие прокурора в суде первой и второй инстанций по гражданским делам. М., 1963.

Васьковский E. В. Курс гражданского процесса. М., 1913.

Buкуm M. A. Правовое положение прокурора, предъявившего иск в интересах другого лица // Вопросы теории и практики прокурорского надзора. 1994. № 10. С. 135.

Bикуm M. A. Стороны - основные лица искового производства. Саратов, 1968.

Власов A. А. Участие прокурора в гражданском и арбитражном судопроизводстве (по ГПК РФ и АПК РФ 2002 г.) : метод. пособие. М., 2004. 
Ергашев E. P. Прокурорский надзор в Российской Федерации. Курс лекций. Екатеринбург, 2016.

Иванов А. Л. Прокурор как лицо, участвующее в деле в российском гражданском судопроизводстве : проблемы определения правового статуса // Вестник Моск. ун-та МВД России. 2009. № 4.

Китаева A. B. Актуальные проблемы участия прокурора в гражданском процессе // Международный научный журнал «Инновационная наука». 2016. № 3 .

Клейнлан А. Ф. Советский гражданский процесс. М., 1954.

Козлов А. Ф. Вопросы гражданского процесса в свете решений XXVII съезда КПСС. Свердловск : Изд-во СГУ, 1987.

Курылев C. В. Объяснения сторон как доказательство в советском гражданском процессе. М., 1956.

Маслова T. Н. Проблемы участия прокурора в гражданском судопроизводстве : дис. ... канд. юрид. наук. Саратов, 2002.

Осокина Г. Л. Гражданский процесс. Общая часть : учебник. 3-е изд., перераб. М. : Норма : ИНФРА-М, 2013.

Рожков А. Ю. Необходимость и целесообразность участия прокурора в гражданском и арбитражном процессе // Вестник Воронеж. ин-та МВД России. 2014. № 2 .

Tолстых A. C. Прокурор в гражданском процессе : современные проблемы. URL: http://docplayer.ru/29445615

Ференс-Сороикий A. A. Прокурор в гражданском судопроизводстве // Правоведение. 1992. № 4.

Чечина Н. А. Гражданский процесс : учебник. Изд. третье, перераб. и доп. М. : ПБОЮЛ, 2001.

Чечот Д. М. Участники гражданского процесса. М. : Госюриздат, 1960.

Шакарян M. C. Субъекты советского гражданского процессуального права. М., 1970.

Шобухин B. О некоторых вопросах участия прокурора в гражданском процессе // Арбитражный и гражданский процесс. 2007. № 3.

Юдельсон К. С. Советский гражданский процесс. М., 1956.

\section{References}

Banchenko-Lyubimova K. S. Participation of the prosecutor in the first and 42 second court instances in civil cases. M., 1963.

Vaskovsky E. V. Civil Procedure Course. M., 1913.

Vikut $M$. A. Legal status of the prosecutor who brought a claim in the interests of another person // Questions of theory and practice of prosecutor's supervision. 1994. № 10. P. 135.

Vikut $M$. A. The parties are the main persons of the claim proceeding. Saratov, 1968.

Vlasov A. A. Participation of a prosecutor in civil and arbitration proceedings (according to the Code of Civil Procedure of the Russian Federation and the Arbitration Procedure Code of the Russian Federation, 2002): Method. allowance. M., 2004.

Ergashev E. R. Prosecutor's supervision in the Russian Federation. Course of lectures. Yekaterinburg, 2016. 
Ivanov $A$. $L$. The prosecutor as a person participating in the case in the Russian civil proceedings: problems of determining the legal status. Bulletin of the Moscow University of the Ministry of Internal Affairs of Russia. 2009. № 4.

Kitaeva A. V. Actual problems of the participation of the prosecutor in the civil process // International scientific journal "Innovative Science". 2016. № 3.

Kleinman A. F. Soviet civil process. M., 1954.

Kozlov A. F. Questions of civil procedure in the light of the decisions of the XXVII Congress of the CPSU. Sverdlovsk: SSU Publishing House, 1987.

Kurylev S. V. Explanations of the parties as evidence in the Soviet civil procedure. M., 1956.

Maslova T. N. Problems of the participation of the prosecutor in civil proceedings : Dis. ... Cand. Jurid. Sciences. Saratov, 2002.

Osokina G. L. Civil procedure. General part: textbook : 3rd ed., Revised. M. : Norma : INFRA-M, 2013.

Rozhkov A. Yu. Necessity and expediency of the participation of the prosecutor in civil and arbitration proceedings // Bulletin of the Voronezh Institute of the Ministry of Internal Affairs of Russia. 2014. No. 2.

Tolstykh A. S. Prosecutor in Civil Procedure : Contemporary Problems. URL: http://docplayer.ru/29445615

Ferens-Sorotsky A. A. Prosecutor in civil proceedings // Jurisprudence. 1992. No. 4.

Chechina N. A. Civil Procedure Textbook Third edition, revised and enlarged. M. : PBOYUL, 2001.

Chechot D. M. Participants of the civil process. M. : Gosyurizdat, 1960.

Shakaryan M. S. Subjects of Soviet civil procedural law. M., 1970.

Shobukhin V. On some issues of the participation of the prosecutor in the civil process // Arbitration and civil process. 2007. No. 3.

Yudelson K. S. Soviet civil procedure. M., 1956.

Уральский государственный юридический университет

Ергашев E. Р., доктор юридических наук, профессор, заведующий кафедрой прокурорской деятельности

E-mail: ergashever@mail.ru
Ural State Law University

Ergashev E. R., Doctor of Legal Sciences, Professor, Head of the Prosecutorial Activities Department

E-mail: ergashever@mail.ru 